\section{Updated dental radiography guideline}

The Faculty of General Dental Practice (UK)'s Selection criteria for dental radiography, the leading text on indications for radiographic investigation in dentistry, has been updated following the implementation of revised regulations on the use of ionising radiation.

The changes are reflected in both the free online version of the guidance and the printed book.

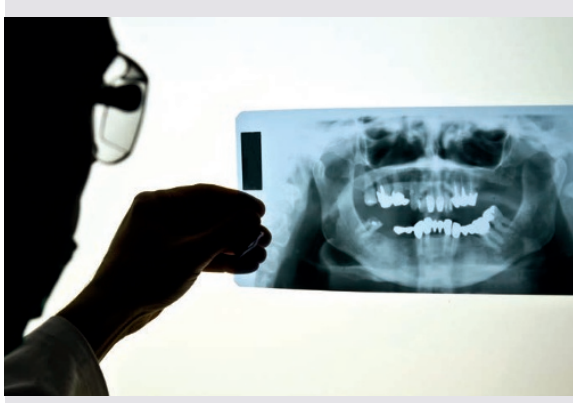

The update to the third edition takes into account the Ionising Radiation Regulations 2017 (IRR17), which took effect on 1 January 2018, and the Ionising Radiation (Medical Exposure) Regulations 2017 (IRMER17), which came into effect on 6 February 2018. IRR17 supersedes IRR99, and IRMER17 has replaced both the original IRMER 2000 and the amendments from 2006 and 2011. Both apply in England, Scotland and Wales; dentists in Northern Ireland should continue to comply with the existing local regulations.

One key change of immediate relevance is that employers are now required to register dental practices with the Health and Safety Executive if they use radiographic equipment. Applications for registration must be made online, incur a one-off fee of $£ 25$, and should have been made by 5 February. The FGDP(UK) is advising any employers yet to register their practice(s) to do so immediately.

https://www.fgdp.org.uk/news/ updated-radiography-guidance.

\title{
The benefits of joining the British College of Aesthetic Medicine
}

\section{The British College of Aesthetic Medicine has around 360 member doctors and has just opened up its membership to dentists. In this personal account, dentist Sami Stagnell ${ }^{1}$ provides an overview of the latest developments.}

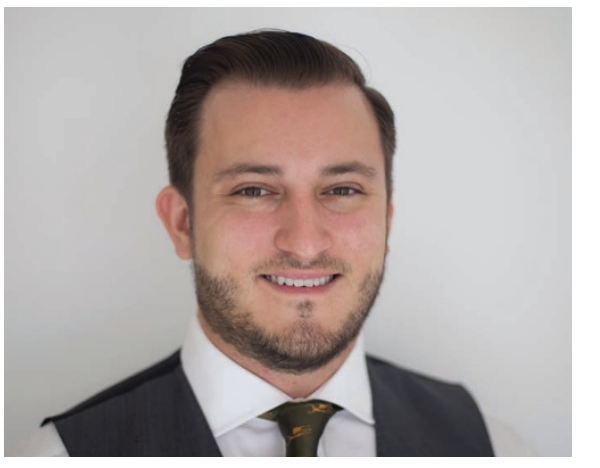

(

ver the last few years, general dentists have found themselves in a position where they are developing their skill sets and portfolios of work in order to provide an ever expanding service to their patients. One area in particular that has grown exponentially is non-surgical facial aesthetics and here we find a field that allows for the overlap of professions and specialties across healthcare, but which also brings with it a minefield of personal development challenges. This is also complicated by changing landscapes: we are due to see major changes to the cosmetic sector with the introduction of the JCCP Register and training standards set by the Joint Council for Cosmetic Practitioners.

Within dentistry we have begun to see improving frameworks for postgraduate education but non-surgical facial aesthetics pose a barrier where many dentists may struggle to understand how to plan and evolve their theoretical and practical skills. This is especially prudent when we consider the recently changed framework for CPD and PDP implemented by the GDC.

With so many changes afoot surrounding the cosmetic sector and the profession, there is a feeling that dentistry needs to find a home within non-surgical facial aesthetics, especially to ensure we continue to provide high levels of care to our patients.
From this year, dentists have been considered eligible to join the British College of Aesthetic Medicine (BCAM) as members, which is an incredible step forwards. We now have an opportunity to join our medical colleagues in developing and improving the cosmetic sector in a joined up and collaborative way.

By belonging to and working with this well-established association, we can engage positively in peer supported activities, improving our networks and enhancing our skills. For those starting out there are training resources through the BCAM academy and as members, access to mentors and support, as well as events such as the annual scientific conference, are unparalleled.

BCAM offers an excellent way forwards for dentists who consider themselves to be high-quality and progressive clinicians and our inclusion into their ranks is a great step forwards for those of us who feel so passionate about cosmetic practice.

BCAM president, Dr Paul Charlson, said: 'I am absolutely delighted that BCAM is now an organisation for doctors and dentists. I think it's important to include dentists because they currently don't have a body to represent them in aesthetics. Also, there is a huge number of dentists practising out there so it's a good opportunity for them to really work with us and increase their skills and knowledge'.

The BCAM annual Conference is taking place on Saturday 22 September 2018 at Church House Westminster, London. More info on the BCAM website: https://bcam.ac.uk/

\footnotetext{
Sami Stagnell is a specialist oral surgeon working on the south coast. He has been practising aesthetic medicine for six years and is currently completing a Masters in Skin Ageing and Aesthetic Medicine with the University of Manchester. He has also been involved in the JCCP stakeholder events representing dental views and is passionate about improving patient safety and clinical outcomes in aesthetics.
} 